\title{
ParaDockS - an open source framework for molecular docking
}

\author{
Martin Pippel ${ }^{1^{*}}$, Michael Scharfe ${ }^{1 *}$, Renè Meier ${ }^{2}$, Wolfgang Sippl ${ }^{1}$ \\ From 7th German Conference on Chemoinformatics: 25 CIC-Workshop \\ Goslar, Germany. 6-8 November 2011
}

The generation and evaluation of molecular complexes in order to predict binding modes of protein ligand complexes, is still a challenging task. Many different algorithms and approaches try to solve the molecular docking problem. Within this work we introduce the open source docking platform ParaDockS (Parallel Docking Suite) [1], that allows the convenient incorporation of existing and new approaches either to describe ligand-receptor interaction or to search for native poses.

The goal of this work pursues the line of thought, that ParaDockS is open source. We want to initiate a highly dynamic community, so that both users and developers contribute with their knowledge and experience to take this very interesting field one step further.

The framework, written in $\mathrm{C}++$, is highly modular designed. This offers an easy access to developers to work only on their area of expertise. ParaDockS provides a functionality to analyze, process and store different kind of input structures.

Another focus is set on the implementation of scoring functions. Beside implemented scoring functions PScore, PMF04 and Drugscore, ParaDockS offers the possibility to derive and apply target specific scoring functions. Therefore, we implemented a workflow to derive target class specific PMF atom-pair potentials. This involves the preparation of complex structures to get an adequate structural database. The definition of atom types and the derivation of pair potentials can completely be accomplished in the upcoming version of ParaDockS. The resulting atom pair potentials can be directly used as scoring function for docking or rescoring approaches. The whole workflow was applied and validated for

\footnotetext{
* Correspondence: martin.pippel@pharmazie.uni-halle.de

'Institute of Pharmacy, Martin-Luther-Universität Halle-Wittenberg, Halle (Saale), 06120, Germany

Full list of author information is available at the end of the article
}

kinases, but is applicable to every target class with enough structural data.

One of the latest improvements involves an interface to the pharmacophor modeling program LigandScout [3]. This offers the big advantage to setup the docking with a great graphical interface, as well the created pharmacophores can be used to guide the docking process.

\section{Author details \\ ${ }^{1}$ Institute of Pharmacy, Martin-Luther-Universität Halle-Wittenberg, Halle (Saale), 06120, Germany. ${ }^{2}$ Institute of Biochemistry, University of Leipzig, Leipzig, 04103, Germany.}

Published: 1 May 2012

\section{References}

1. Meier, Pippel, Brandt, Sippl, Baldauf: ParaDockS - A framework for Molecular Docking with Population-Based Metaheuristics. J Chem Inf Model 2010, 50:879-889.

2. Muegge I: PMF Scoring Revisited. J Med Chem 2006, 49:5895-5902.

3. Wolber G, Langer T: LigandScout: 3-D Pharmacophores Derived from Protein-Bound Ligands and Their Use as Virtual Screening Filters. J Chem Inf Model 2005, 45:160-169.

doi:10.1186/1758-2946-4-S1-F3

Cite this article as: Pippel et al:: ParaDockS - an open source framework for molecular docking. Journal of Cheminformatics 2012 4(Suppl 1):F3.

\section{Publish with ChemistryCentral and every scientist can read your work free of charge \\ "Open access provides opportunities to our colleagues in other parts of the globe, by allowing anyone to view the content free of charge." \\ W. Jeffery Hurst, The Hershey Company.}

- available free of charge to the entire scientific community

- peer reviewed and published immediately upon acceptance

- cited in PubMed and archived on PubMed Central

- yours - you keep the copyright

Submit your manuscript here:

http://www.chemistrycentral.com/manuscript/

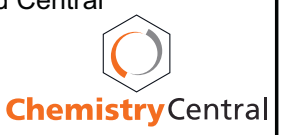

